\title{
Vigilin interacts with signal peptide peptidase
}

\author{
Stephen Hsueh-Jeng Lu', Amy Hye Won Jeon², Gerold Schmitt-Ulms², Seema Qamar', Roger Dodd ${ }^{1}$, \\ Beth McDonald ${ }^{1}$, Yi Li ${ }^{1}$, William Meadows ${ }^{1}$, Katie Cox ${ }^{1}$, Christopher Bohm², Fusheng Chen², Paul Fraser ${ }^{2}$ \\ and Peter St George-Hyslop ${ }^{1,2^{*}}$
}

\begin{abstract}
Background: Signal peptide peptidase (SPP), a member of the presenilin-like intra-membrane cleaving aspartyl protease family, migrates on Blue Native (BN) gels as $100 \mathrm{kDa}, 200 \mathrm{kDa}$ and $450 \mathrm{kDa}$ species. SPP has recently been implicated in other non-proteolytic functions such as retro-translocation of MHC Class I molecules and binding of misfolded proteins in the endoplasmic reticulum (ER). These high molecular weight SPP complexes might contain additional proteins that regulate the proteolytic activity of SPP or support its non-catalytic functions.
\end{abstract}

Results: In this study, an unbiased iTRAQ-labeling mass spectrometry approach was used to identify SPP-interacting proteins. We found that vigilin, a ubiquitous multi-KH domain containing cytoplasmic protein involved in RNA binding and protein translation control, selectively enriched with SPP. Vigilin interacted with SPP and both proteins co-localized in restricted intracellular domains near the ER, biochemically co-fractionated and were part of the same $450 \mathrm{kDa}$ complex on BN gels. However, vigilin does not alter the protease activity of SPP, suggesting that the SPP-vigilin interaction might be involved in the non-proteolytic functions of SPP.

Conclusions: We have identified and validated vigilin as a novel interacting partner of SPP that could play an important role in the non-proteolytic functions of SPP. This data adds further weight to the idea that intramembrane-cleaving aspartyl proteases, such as presenilin and SPPs, could have other functions besides the proteolysis of short membrane stubs.

Keywords: Signal peptide peptidase, Vigilin, Biochemistry, Intramembrane-cleaving aspartyl protease, Non-proteolytic function, Interactome

\section{Background}

Signal peptide peptidase (SPP) [1] is a member of the intramembrane cleaving aspartyl protease family that also includes the presenilins and SPP-like proteases. Members of this family share characteristic YD, GxGD and PAL motifs [2]. However, the presenilins cleave Type I transmembrane proteins [3], while the SPP-like proteases cleave Type II transmembrane proteins [1]. Amongst the SPP-like proteases, the ER-resident SPP is thought to cleave the membrane-bound stubs of some secreted proteins following proteolysis of the signal peptide by the signal peptidase [1,4], and in doing so

\footnotetext{
* Correspondence: phs22@cam.ac.uk
${ }^{1}$ Cambridge Institute for Medical Research, Department of Clinical

*Correspondence: phs22@cam.ac.uk
'Cambridge Institute for Medical Research, Department of Clinical

Neurosciences, University of Cambridge, Addenbrooke's Hospital, Hills Road, England, Cambridge CB2 OXY, United Kingdom

${ }^{2}$ Tanz Centre for Research in Neurodegenerative Diseases, and Departments
of Medicine, Laboratory Medicine and Pathobiology, and Medical Biophysics,

${ }^{2}$ Tanz Centre for Research in Neurodegenerative Diseases, and Departments
of Medicine, Laboratory Medicine and Pathobiology, and Medical Biophysics, University of Toronto, 6 Queen's Park Crescent West, Toronto, ON M5S 3H2, Canada
}

(C) 2012 Lu et al.; licensee BioMed Central Ltd. This is an Open Access article distributed under the terms of the Creative Commons Attribution License (http://creativecommons.org/licenses/by/2.0), which permits unrestricted use, distribution, and reproduction in any medium, provided the original work is properly cited.

presumably releases the stubs from the ER membrane. SPP may also have additional activities in protein control in the ER. For example, SPP is required for the dislocation or retro-translocation of MHC Class I molecules in the presence of the human cytomegalovirus (hCMV) US2 protein [5]. Others have reported that both catalytically inactive and wild-type SPP may bind and stabilize misfolded membrane proteins [6,7].

Preliminary biochemical and biophysical studies by this and other groups [7] have revealed that the SPP-like proteases in general, and SPP in particular, exist in cell lysates as higher molecular mass species than would be predicted from the calculated molecular weight of their respective monomeric polypeptides (Figure 1 ). One potential explanation for this observation is that the SPP proteins might exist as dimers $[8,9]$ or higher order assemblies. However, this observation also raises the possibility that there may be ancillary proteins which, although not required for SPP proteolytic activity, may

\section{Biomed Central}




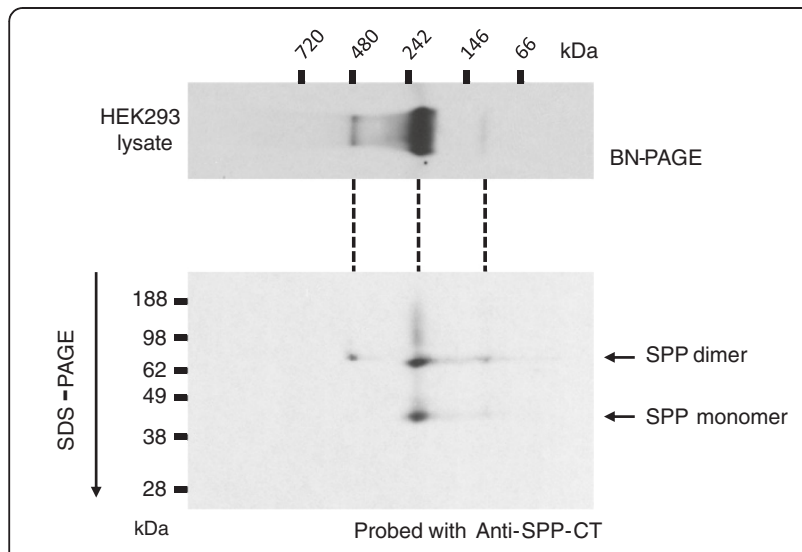

Figure 1 SPP exists in higher molecular weight complexes. Top panel, HEK293 lysate solubilized in 0.5\% DDM and resolved on 16\% Bis-Tris Blue Native-PAGE gels, revealing SPP-containing complexes at around $450 \mathrm{kDa}, 200 \mathrm{kDa}$ and $100 \mathrm{kDa}$. Lower panel, lysates resolved on the BN-PAGE were then resolved on the second dimension/SDSPAGE. SDS-stable SPP dimer can be found in all three high molecular weight bands suggesting that the $100 \mathrm{kDa}$ band observed in the first dimension is a SDS-stable SPP dimer.

nevertheless modulate its function. We therefore set out to determine whether the high molecular weight SPP complexes might contain other proteins, and if so, whether these other proteins modulated the SPP protease activity function of the SPPs. Using an unbiased mass spectrometry (MS) based approach, vigilin was identified as a candidate SPP interacting protein. Reciprocal coimmunoprecipitations confirmed the interaction between SPP and vigilin. Additionally, SPP and vigilin co-localized in restricted cellular domains, co-fractionated biochemically and co-migrated as a single band on $\mathrm{BN}$ gels.

\section{Results}

Isolation of endogenous SPP complexes

SPP and its potential interacting partners were isolated from native HEK293 cells using a single-step affinity purification protocol (for a schematic of the protocol see Figure 2A). Specifically, microsomal membrane isolates were solubilized in $0.5 \% \mathrm{~N}$-Dodecyl- $\beta$-D-maltoside (DDM) and subjected to anti-SPP affinity purification using anti-SPP-CT antibody, which recognizes the Cterminal amino acids $358-377$ of SPP. In order to generate the negative control with which to identify and exclude non-specific binders, the capture antibody was pre-blocked with cognate peptide in the control purification, and the cognate peptide was further included during the subsequent affinity matrix washing step. The purified SPP proteins were resolved by SDS-PAGE and visualized by Western blotting and silver staining (Figure 2B). In eluates obtained following SPP-specific capture, SPP-immunoreactive bands were observed at $42 \mathrm{kDa}$ for monomeric SPP (predicted to be $47 \mathrm{kDa}$ ) and at $70 \mathrm{kDa}$, interpreted to be SDS-stable dimers. The discrepancy between the actual molecular weight

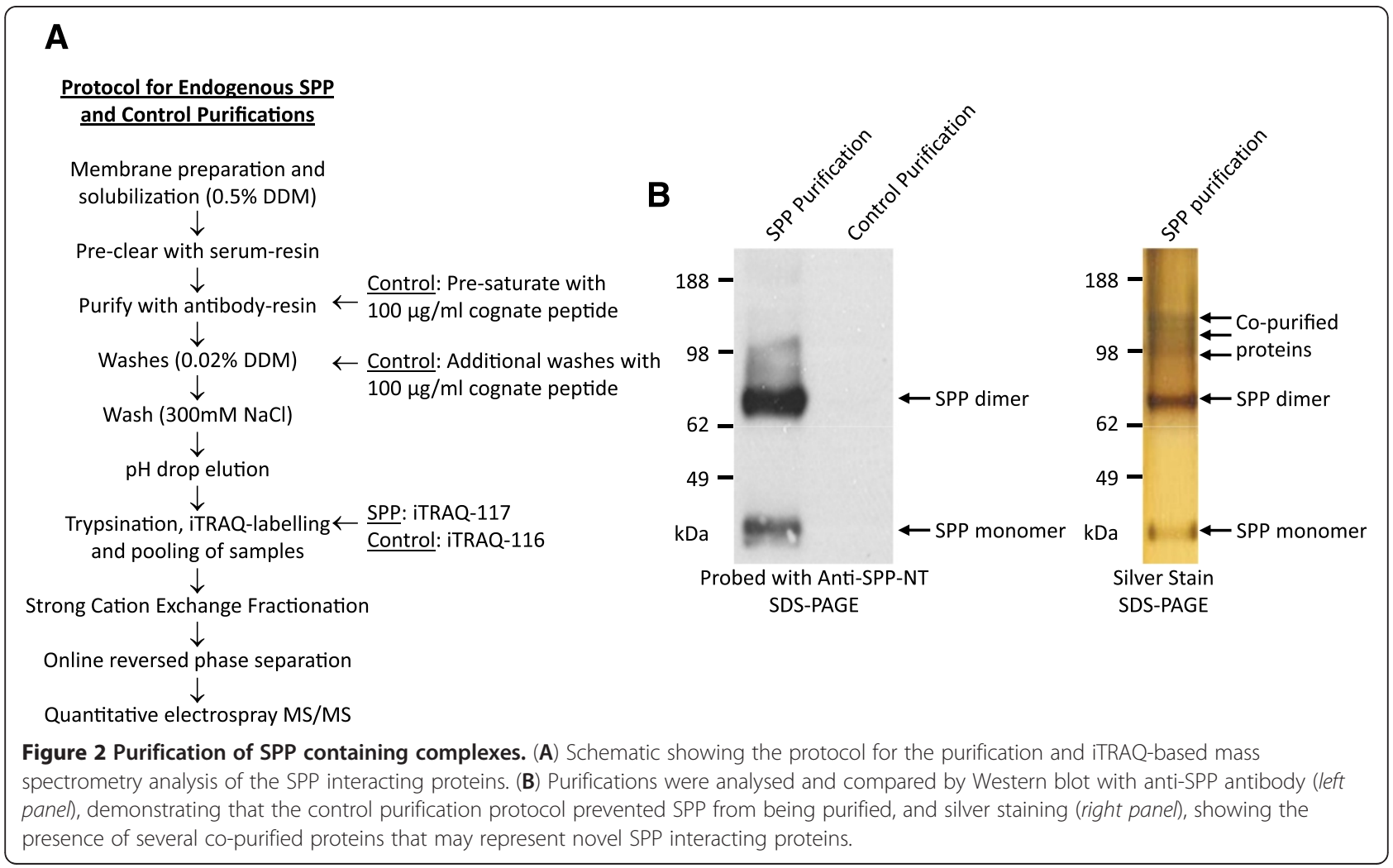


and the observed molecular weight on SDS-PAGE is a common observation, in particular for membrane proteins, and in part reflects the effect of bound detergent [10]. However, in the control purification, no SPP signal was observed, demonstrating that the cognate peptide was able to block the isolation of SPP. Parenthetically, this method was used because it was much more effective at reducing SPP binding in the control purification than siRNA knockdown of SPP (data not shown). The identity of the co-purified proteins and their level of enrichment in the cognate-peptide-blocked control equipment were then determined by iTRAQ-labelling coupled with mass spectrometry (Figure 3A).

\section{iTRAQ-based analysis of the interactome of SPP}

Inspection of the iTRAQ data revealed a robust enrichment of SPP (HM13) (for a list of proteins identified and their iTRAQ 117:116 ratios, see Table 1 and Additional file 1), while non-specific binders such as the frequently encountered protein HSP70, had iTRAQ 117:116 ratios for the signature mass peaks of less than 1.5 (Figure 3A). However, selective co-enrichment $(117: 116$ ratios $\geq 1.5)$ of the ubiquitous $140 \mathrm{kDa}$ RNA-binding protein vigilin was observed together with SPP (Figure 3B). Thirteen unique peptides were identified from vigilin in total (Figure 3C).

\section{Vigilin physically interacts with SPP}

To validate the iTRAQ results, reciprocal co-immunoprecipitation experiments from HEK293 cells were undertaken. As expected, endogenous vigilin was captured when using endogenous SPP as the bait protein (Figure 4A). The reciprocal co-immunoprecipitation experiments using anti-vigilin antibody was inconclusive because the SPP bands migrated very closely to the denatured IgG, making it difficult to differentiate SPP bands

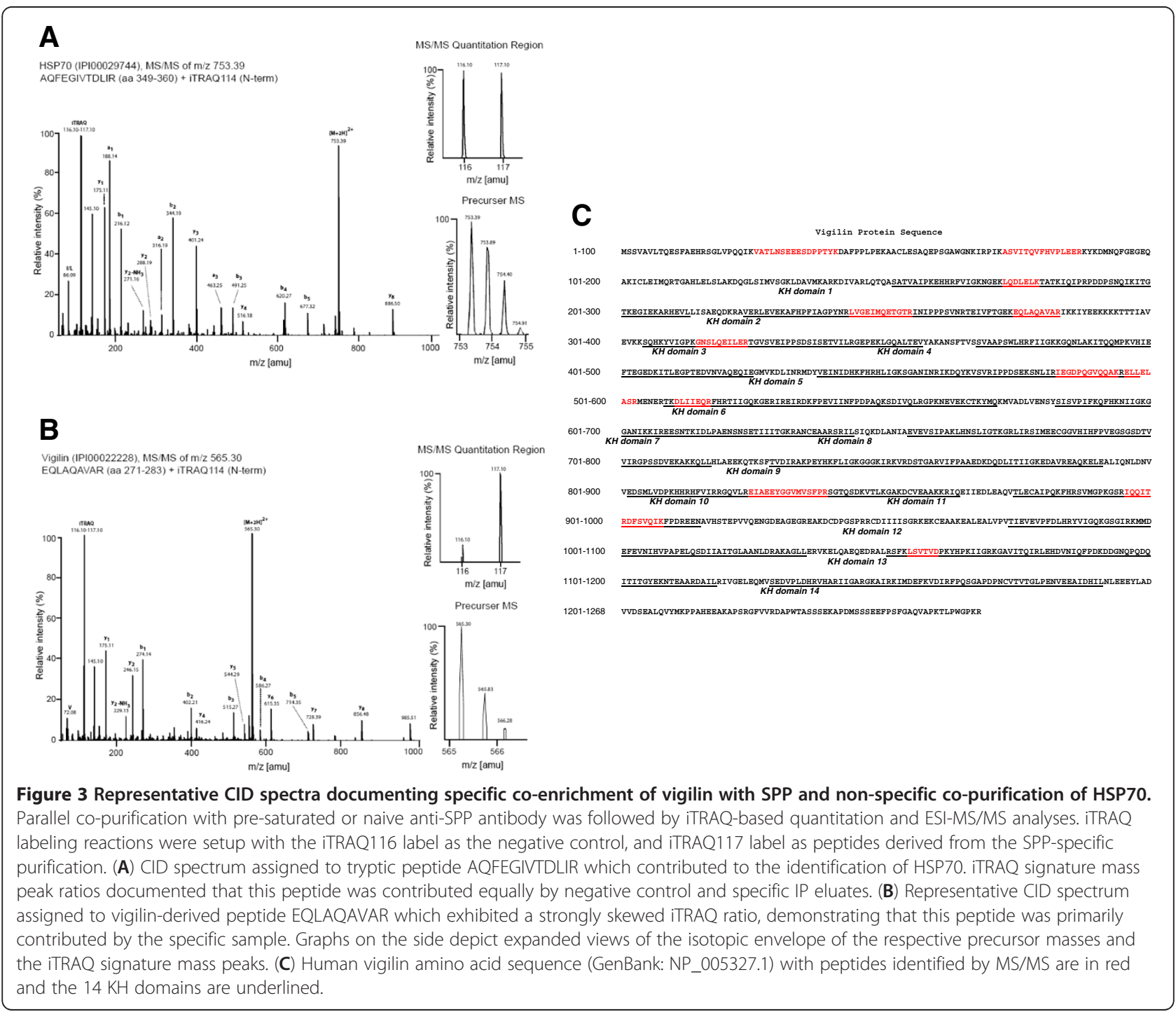


Table 1 List of proteins identified in the ITRAQ mass spectrometry analysis of SPP interacting proteins

\begin{tabular}{|c|c|c|c|c|c|}
\hline Protein Name & Accession Number & Symbol & Unique Peptides & Coverage (\%) & iTRAQ Ratio (117:116) \\
\hline Signal peptide peptidase & IPI:IPI00152441.3 & SPP & 6 & 22.0 & 331.3 \\
\hline Vigilin & IPI:IPI00022228.1 & VIGLN & 13 & 14.6 & 4.3 \\
\hline $\begin{array}{l}10 \mathrm{kDa} \text { heat shock protein, } \\
\text { mitochondrial }\end{array}$ & IPI:IPI00220362.4 & HSPE1 & 9 & 72.3 & 1.4 \\
\hline Microfibrillar-associated protein 1 & IPI:IPI00022790.1 & MFAP1 & 5 & 20.3 & 1.3 \\
\hline Heat shock protein 60 & IPI:IPI00472102.3 & HSP60 & 23 & 63.8 & 1.2 \\
\hline Calnexin precursor & IPI:IPI00020984.1 & CNX & 9 & 15.5 & 1.1 \\
\hline Alpha-enolase & IPI:IPI00465248.4 & ENO1 & 14 & 37.2 & 1.1 \\
\hline $\begin{array}{l}\text { Glyceraldehyde-3-phosphate } \\
\text { dehydrogenase }\end{array}$ & IPI:IPI00219018.6 & GAPDH & 8 & 33.5 & 1.1 \\
\hline Protein C14orf166 & IPI:IPI00006980.1 & C14orf166 & 7 & 39.8 & 1.1 \\
\hline $\begin{array}{l}\text { Stress-70 protein, mitochondrial } \\
\text { precursor }\end{array}$ & IPI:IPI00007765.5 & HSPA9 & 43 & 71.4 & 1.0 \\
\hline $\begin{array}{l}\text { Eukaryotic translation initiation } \\
\text { factor } 4 \text { gamma } 1\end{array}$ & IPI:IPI00552639.2 & EIF4G1 & 8 & 13.6 & 1.0 \\
\hline $\begin{array}{l}\text { ATP synthase O subunit, } \\
\text { mitochondrial precursor }\end{array}$ & IPI:IPI00007611.1 & ATP5O & 10 & 59.1 & 1.0 \\
\hline Actin, cytoplasmic 1 & IPI:IP|00021439.1 & ACTB & 9 & 47.5 & 1.0 \\
\hline 130 kDa leucine-rich protein & IPI:IPI00329745.4 & LPPRC & 11 & 12.8 & 1.0 \\
\hline Sideroflexin-1 & IPI:IPI00009368.3 & SFXN1 & 8 & 31.8 & 0.9 \\
\hline $\begin{array}{l}\text { ATP-dependent DNA helicase } \\
2 \text { subunit } 1\end{array}$ & IPI:IP|00644712.3 & Ku70 & 11 & 20.7 & 0.9 \\
\hline Prohibitin & IPI:IPI00017334.1 & $\mathrm{PHB}$ & 8 & 34.2 & 0.9 \\
\hline Heat shock 70 kDa protein 1 & IPI:IPI00643932.1 & HSP70-1 & 29 & 49.3 & 0.9 \\
\hline Splice Isoform 2 of Nucleophosmin & IPI:IPI00220740.1 & NPM1 & 8 & 41.5 & 0.9 \\
\hline Protein disulfide-isomerase & IPI:IPI00010796.1 & PDIA3 & 24 & 30.7 & 0.9 \\
\hline $\begin{array}{l}\text { ATP synthase beta chain, } \\
\text { mitochondrial precursor }\end{array}$ & IPI:IPI00303476.1 & ATP5B & 9 & 29.7 & 0.9 \\
\hline 14-3-3 protein zeta/delta & IPI:IPI00021263.3 & YWHAZ & 7 & 45.3 & 0.9 \\
\hline $\begin{array}{l}\text { NADH-ubiquinone oxidoreductase } \\
24 \mathrm{kDa} \text { subunit, } \\
\text { mitochondrial precursor }\end{array}$ & IPI:IPI00646556.1 & NDUFV2 & 7 & 38.5 & 0.9 \\
\hline Heat shock 70 kDa protein 5 & IPI:IPI00003362.2 & HSPA5 & 26 & 52.1 & 0.9 \\
\hline ATP-dependent RNA helicase A & IPI:IPI00215638.5 & $\mathrm{DH} \times 9$ & 12 & 16.4 & 0.8 \\
\hline $\begin{array}{l}\text { Splice Isoform } 1 \text { of Heat shock } \\
\text { cognate } 71 \mathrm{kDa} \text { protein }\end{array}$ & IPI:IPI00003865.1 & HSPA8 & 16 & 51.4 & 0.8 \\
\hline ATP-dependent RNA helicase DDX3X & IPI:IPI00215637.4 & DDX3X & 8 & 15.9 & 0.8 \\
\hline Vimentin & IPI:IPI00646867.1 & VIM & 12 & 28.1 & 0.8 \\
\hline $\begin{array}{l}\text { Splice Isoform A1-A of Heterogeneous } \\
\text { nuclear ribonucleoprotein A1 }\end{array}$ & IPI:IPI00465365.3 & HNRNPA1 & 12 & 64.6 & 0.8 \\
\hline protein kinase $\mathrm{C}$ substrate $80 \mathrm{~K}-\mathrm{H}$ isoform 1 & IPI:IP|00419384.1 & PRKCSH & 11 & 23.7 & 0.8 \\
\hline Programmed cell death 8 & IPI:IPI00157908.3 & PDCD8 & 7 & 14.6 & 0.8 \\
\hline peroxiredoxin 3 isoform b & IPI:IPI00374151.1 & PRDX3 & 8 & 34.0 & 0.8 \\
\hline FK506-binding protein 10 & IPI:IPI00303300.3 & FKBP10 & 8 & 21.6 & 0.8 \\
\hline Elongation factor 2 & IPI:IPI00186290.5 & $\mathrm{EEF} 2$ & 12 & 20.3 & 0.8 \\
\hline Reticulocalbin-1 & IPI:IP|00015842.1 & RCN1 & 6 & 19.6 & 0.8 \\
\hline Splice Isoform 1 of Apoptosis inhibitor 5 & IPI:IPI00555572.1 & API5 & 9 & 24.7 & 0.8 \\
\hline Citrate synthase, mitochondrial precursor & IPI:IPI00025366.4 & CS & 8 & 19.3 & 0.8 \\
\hline
\end{tabular}


Table 1 List of proteins identified in the ITRAQ mass spectrometry analysis of SPP interacting proteins (Continued)

\begin{tabular}{|c|}
\hline Transitional endoplasmic reticulum ATPase \\
\hline $\begin{array}{l}\text { Single-stranded DNA-binding protein, } \\
\text { mitochondrial precursor }\end{array}$ \\
\hline Fructose-bisphosphate aldolase A \\
\hline Creatine kinase B-type \\
\hline Neutral alpha-glucosidase $A B$ precursor \\
\hline 14-3-3 protein epsilon \\
\hline Nuclease sensitive element-binding protein 1 \\
\hline Spliceosome RNA helicase BAT1 \\
\hline Nucleolin \\
\hline ADP/ATP translocase 2 \\
\hline Prohibitin-2 \\
\hline ADP/ATP translocase 3 \\
\hline $\begin{array}{l}\text { Splice Isoform } 2 \text { of Heterogeneous } \\
\text { nuclear ribonucleoprotein K }\end{array}$ \\
\hline peptidylprolyl isomerase B \\
\hline Peroxiredoxin-1 \\
\hline $\begin{array}{l}\text { Mitochondrial precursor proteins } \\
\text { import receptor }\end{array}$ \\
\hline $\begin{array}{l}\text { Splice Isoform } 1 \text { of } \\
\text { Polyadenylate-binding protein } 1\end{array}$ \\
\hline $\begin{array}{l}\text { Splice Isoform } 3 \text { of DNA-binding } \\
\text { protein A }\end{array}$ \\
\hline $\begin{array}{l}\text { Splice Isoform } 3 \text { of Interleukin } \\
\text { enhancer-binding factor } 3\end{array}$ \\
\hline $\begin{array}{l}\text { Splice Isoform } 2 \text { of Probable } \\
\text { ATP-dependent RNA helicase DDX17 }\end{array}$ \\
\hline $40 \mathrm{~S}$ ribosomal protein $\mathrm{S} 10$ \\
\hline Elongation factor 1-alpha 1 \\
\hline Endoplasmin \\
\hline $\begin{array}{l}\text { Dihydrolipoyllysine-residue succinyltransferase } \\
\text { component of 2- oxoglutarate dehydrogenase } \\
\text { complex, mitochondrial precursor }\end{array}$ \\
\hline $\begin{array}{l}\text { Splice Isoform B1 of Heterogeneous nuclear } \\
\text { ribonucleoproteins A2/B1 }\end{array}$ \\
\hline $\begin{array}{l}\text { Splice Isoform Long of Splicing factor, } \\
\text { proline- and glutamine-rich }\end{array}$ \\
\hline CKAP4 protein (Fragment) \\
\hline Calreticulin \\
\hline Protein disulfide-isomerase A6 \\
\hline $\begin{array}{l}\text { ATP synthase alpha chain, } \\
\text { mitochondrial precursor }\end{array}$ \\
\hline Nucleobindin-2 \\
\hline $40 S$ ribosomal protein SA \\
\hline $\begin{array}{l}\text { Splice Isoform C1 of Heterogeneous nuclear } \\
\text { ribonucleoproteins C1/C2 }\end{array}$ \\
\hline Heterogeneous nuclear ribonucleoprotein $G$ \\
\hline $\begin{array}{l}\text { Serine hydroxymethyltransferase, } \\
\text { mitochondrial precursor }\end{array}$ \\
\hline
\end{tabular}

\begin{tabular}{|c|c|c|c|c|}
\hline IPI:IPI00478540.2 & VCP & 8 & 13.9 & 0.8 \\
\hline IPI:IPI00029744.1 & SSBP1 & 10 & 74.3 & 0.8 \\
\hline IPI:IPI00465439.4 & ALDOA & 6 & 26.7 & 0.8 \\
\hline IPI:IPI00022977.1 & CKB & 6 & 23.1 & 0.8 \\
\hline IPI:IPI00472068.1 & GANAB & 8 & 16.0 & 0.8 \\
\hline IPI:IPI00000816.1 & YWHAE & 9 & 51.4 & 0.7 \\
\hline IPI:IPI00031812.2 & NSEP1 & 7 & 48.6 & 0.7 \\
\hline IPI:IPI00328343.7 & DDX39B & 9 & 22.2 & 0.7 \\
\hline IPI:IPI00743912.1 & $\mathrm{NCL}$ & 16 & 31.9 & 0.7 \\
\hline IPI:IPI00007188.4 & SLC25A5 & 9 & 35.4 & 0.7 \\
\hline IPI:IPI00027252.6 & PHB2 & 8 & 43.8 & 0.7 \\
\hline IPI:IPI00291467.6 & SLC25A6 & 9 & 35.4 & 0.7 \\
\hline IPI:IPI00216746.1 & HNRPK & 12 & 41.8 & 0.7 \\
\hline IPI:IPI00646304.3 & PPIB & 7 & 40.7 & 0.7 \\
\hline IPI:IPI00000874.1 & PRDX1 & 6 & 34.7 & 0.7 \\
\hline IPI:IPI00015602.1 & TOMM70A & 11 & 26.2 & 0.7 \\
\hline IPI:IPI00008524.1 & PABPC1 & 14 & 29.2 & 0.7 \\
\hline IPI:IPI00219148.2 & CSDA & 6 & 31.3 & 0.7 \\
\hline IPI:IPI00414335.1 & ILF3 & 9 & 16.2 & 0.7 \\
\hline IPI:IPI00651677.1 & DDX17 & 7 & 19.9 & 0.7 \\
\hline IPI:IPI00008438.1 & RPS10 & 7 & 49.1 & 0.7 \\
\hline IPI:IPI00472724.1 & EEF1A1 & 8 & 22.5 & 0.7 \\
\hline IPI:IPI00027230.3 & HSP90B1 & 23 & 32.7 & 0.7 \\
\hline IPI:IPI00420108.4 & DLSTP1 & 9 & 31.8 & 0.7 \\
\hline IPI:IPI00396378.3 & HNRNPA2B1 & 19 & 57.5 & 0.7 \\
\hline IPI:IPI00010740.1 & SFPQ & 26 & 50.2 & 0.7 \\
\hline IPI:IPI00433214.1 & CKAP4 & 16 & 34.3 & \\
\hline IPI:IPI00020599.1 & CALR & 6 & 25.2 & 0.6 \\
\hline IPI:IPI00644989.1 & PDIA6 & 9 & 27.7 & 0.6 \\
\hline IPI:IPI00440493.2 & ATP5A1 & 15 & 36.7 & \\
\hline IPI:IPI00009123.1 & NUCB2 & 5 & 23.6 & 0.6 \\
\hline IPI:IPI00553164.3 & RPSA & 7 & 39.1 & 0.6 \\
\hline IPI:IPI00216592.1 & HNRNPC & 12 & 52.9 & \\
\hline IPI:IPI00304692.1 & RBMX & 16 & 49.1 & 0.6 \\
\hline IPI:IPI00002520.1 & SHMT2 & 7 & 17.9 & \\
\hline IPI:IPI00009904.1 & PDIA4 & 15 & 35.7 & \\
\hline
\end{tabular}


Table 1 List of proteins identified in the iTRAQ mass spectrometry analysis of SPP interacting proteins (Continued)

\begin{tabular}{|c|c|c|c|c|c|}
\hline Proliferation-associated protein 2G4 & IPI:IPI00299000.4 & PA2G4 & 14 & 36.6 & 0.5 \\
\hline $\begin{array}{l}\text { Non-POU domain-containing } \\
\text { octamer-binding protein }\end{array}$ & IPI:IPI00304596.3 & NONO & 18 & 42.0 & 0.5 \\
\hline Histone H1.2 & IPI:IPI00217465.4 & HIST1H1C & 5 & 34.0 & 0.5 \\
\hline $\begin{array}{l}\text { Complement component } 1 \text {, } \\
\text { Q subcomponent-binding protein, } \\
\text { mitochondrial precursor }\end{array}$ & IPI:IPI00014230.1 & C1QBP & 6 & 42.9 & 0.5 \\
\hline THO complex subunit 4 & IPI:IPI00328840.7 & THOC4 & 7 & 37.1 & 0.4 \\
\hline
\end{tabular}

Vigilin or SPP-derived peptides were selectively enriched in the SPP purification sample compared to the control purification, while all other proteins identified had iTRAQ 117:116 ratios of less than 1.5 .

from non-specific IgG bands. In order to detect vigilin interacting with SPP after vigilin immunoprecipitation, we generated a HEK293 cell line that stably expressed FLAG-tagged vigilin. Expression pattern of FLAG-tagged vigilin in this cell line was similar to the expression pattern of the endogenous vigilin (compare Figure 5A and Figure 5B), and allowed the use of mouse anti-FLAG antibody, instead of the rabbit anti-vigilin antibody. Similar to the endogenous SPP co-immunoprecipitation experiments, the capture with anti-SPP antibody was able to specifically co-immunoprecipitate vigilin-FLAG and SPP while no bands were observed from control coimmunoprecipitations with pre-immune rabbit serum (Figure 4B). Also, this interaction is a specific because SPPL2b did not co-immunoprecipitates with vigilin, but additional SPP-like proteases will need to be tested to determine the extent of this specificity (Figure 4B). Co- immunoprecipitation experiments using anti-FLAG antibody (Figure 4C) captured vigilin-FLAG as well as its interacting partner SPP. Interestingly, the FLAG IP captured predominantly dimers and trimers of SPP but not monomers.

\section{Vigilin can be found in the ER fraction and co-localizes with SPP}

To further explore the possibility of an in vivo vigilinSPP interaction, subcellular iodixanol gradient fractionation studies were performed. In agreement with prior data showing that SPP was ER resident [11-13], SPP was found in fractions containing the ER marker calnexin, but was absent from the cytoplasmic and Golgi fractions (Figure 5A). Vigilin, as expected, was predominantly found in the cytoplasmic fractions. However, in agreement with this prior data, a small proportion of
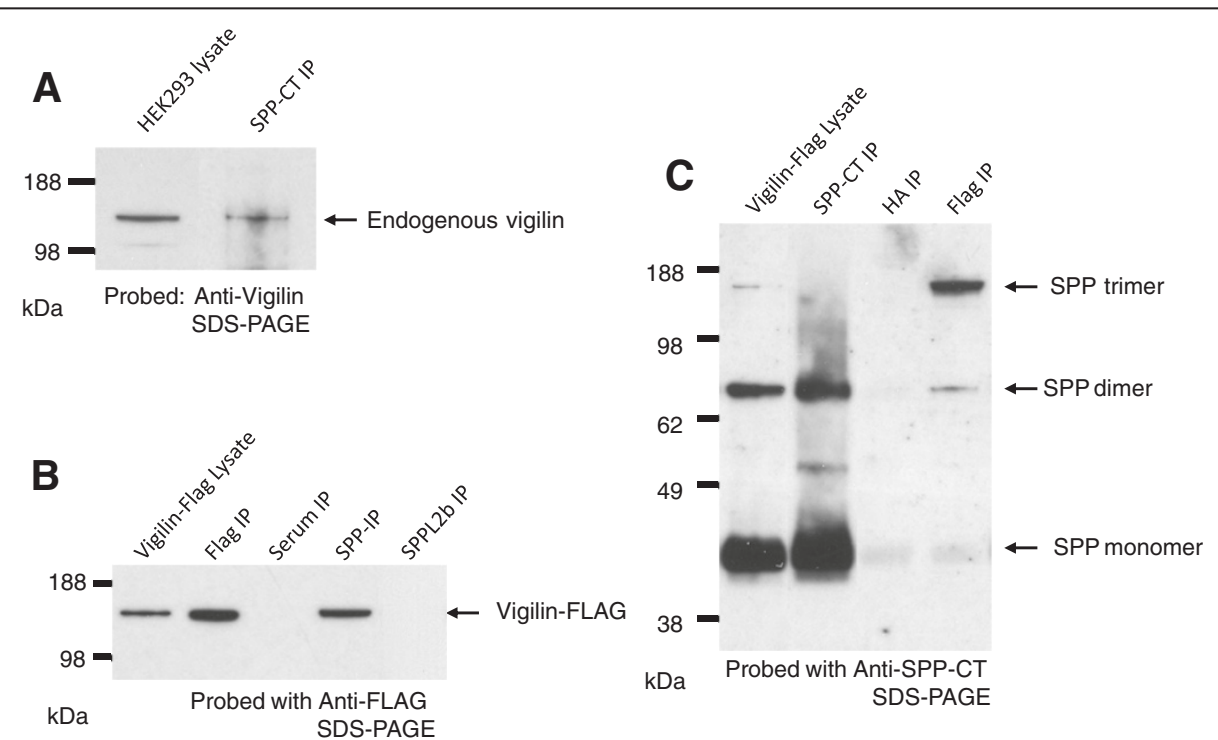

Figure 4 SPP interacts with vigilin. (A) Co-immunoprecipitation with anti-SPP-CT antibody pulled down endogenous vigilin. The blot was probed with anti-vigilin antibody. HEK293 cell lysate was used to align the band. (B) In a HEK293 cell line stably expressing FLAG-tagged vigilin, co-immunoprecipitation with anti-SPP-CT antibody pulls-down vigilin-FLAG, while antibody against SPPL2b did not pull down vigilin-Flag. The blot was probed with anti-FLAG antibody. (C) Co-immunoprecipitation with anti-FLAG antibody pulled-down SDS-stable SPP dimers and trimers in the FLAG-tagged vigilin expressing HEK293 cell line. The blot was probed with anti-SPP-CT antibody. Data shown are representative blots from three independent experiments. 


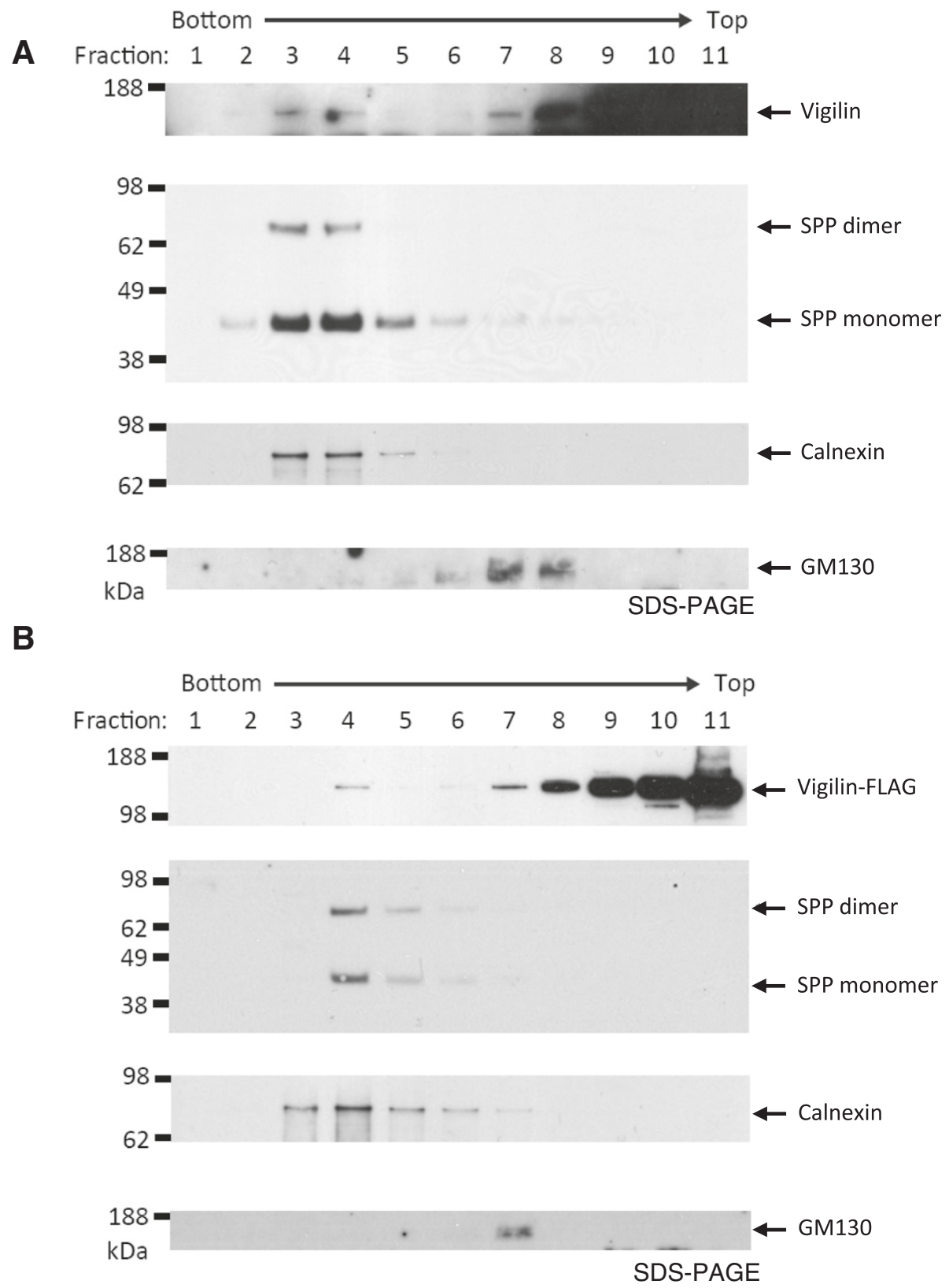

Figure 5 Vigilin is found in ER fraction. (A) HEK293 cells were homogenized and fractionated on an iodixanol gradient. Fractions were collected drop-wise and probed for vigilin, ER-resident SPP, ER-marker calnexin and Golgi apparatus-marker GM130. Vigilin was primarily found in the later (upper) fractions but a small proportion was present in the fractions 3 and 4, which also contained the peak fractions of SPP and calnexin. (B) HEK293 stably expressing vigilin-FLAG were homogenized and fractionated on an iodixanol gradient. Fractions were collected drop-wise and probed for vigilin (using anti-FLAG antibody), SPP, calnexin and GM130. Identical to the endogenous vigilin and SPP distribution, the FLAG-tagged vigilin was found mainly in the cytoplasmic fractions but also found in fraction 4, which also contained the peak fractions of SPP and calnexin.

endogenous vigilin also co-fractionated in the ER membrane fractions along with SPP and calnexin. The fractions containing peak levels of the ER-bound vigilin also corresponded to the fractions containing the peak levels of SPP and calnexin. This result was not due to 'leakage' between the fractions or mixing during the collection of the fractions because there was a gap of 2-3 fractions where vigilin was not present in the collected fractions. Identical results were obtained for the FLAG-tagged vigilin cell line, thereby indicating that the expression of the FLAG-tagged vigilin had not caused it to be mislocalized (Figure 5B). 
To corroborate this biochemical evidence for an interaction, immunofluorescence studies in the HEK293 cells were performed in order to query whether colocalization of SPP and vigilin can be documented. Immunofluorescence studies were not possible with native cells expressing endogenous vigilin because the antibodies against SPP and vigilin were both raised in rabbits. Moreover, while the available anti-vigilin antibodies detect authentic vigilin-immunoreactive bands on Western blots, they also detect a few other weak non-specific bands. This raised the concern that the immunofluorescence studies could be misled by these non-specific epitopes. Consequently, we investigated the localisation of FLAG-tagged vigilin. As noted above, this strategy was safe because the biochemical fractionations studies demonstrated that neither the presence FLAG-tag nor the over-expression of the FLAG-tagged vigilin caused changes in the localisation of vigilin. In HEK293 cells expressing FLAG-tagged vigilin, the majority of the vigilin signal (green signal in Figure 6) was present in the cytoplasm, whereas the SPP signal (red signal in Figure 6) was in the ER. Nevertheless, a small proportion of SPP and vigilin showed co-localization as discrete small round foci on ER structures (yellow dots highlighted with white arrows in Figure 6). This association of vigilin with ER membranes has been previously documented [11-13].

\section{Vigilin is part of the $450 \mathrm{kDa}$ SPP complex}

To determine whether vigilin was a component of any of the three SPP high molecular weight SPP complexes (450 kDa, $200 \mathrm{kDa}$ and $100 \mathrm{kDa}$; Figure 1), cell lysates were resolved on BN-PAGE and probed for vigilin and SPP (Figure 7). These studies revealed that vigilin specifically co-migrates with the $450 \mathrm{kDa}$ band of SPP with both native HEK293 and vigilin-FLAG lysates. Of note, the observed co-migration of SPP and vigilin in this analysis was not due to a non-specific compression of protein bands that can sometimes be observed on the $\mathrm{BN}$ gels (and appeared to account in this analysis for the 700 $\mathrm{kDa}$ band in the Coomassie-stained HEK293 lysates) (Figure 7A). Furthermore, because vigilin co-migrated only with the $450 \mathrm{kDa}$, and not with the more abundant $200 \mathrm{kDa}$ and $100 \mathrm{kDa}$ SPP complexes, this result argued against an artifactual interaction between vigilin and SPP. Indeed, it demonstrates that vigilin is a specific component of the high molecular weight SPP complex.

\section{Vigilin does not affect the aspartyl protease activity of SPP}

To determine if vigilin affects the proteolytic activity of SPP, we performed an in vitro SPP activity assay using a peptide substrate derived from the signal peptide of prolactin [14]. The SPP activity of lysates from mocktransfected HEK293 cells and cells transfected with vigilin-specific siRNAs or vigilin-FLAG expression plasmids were compared (Figure 8). No significant changes in the band intensities of the expected prolactin substrate cleavage products were observed.

\section{Discussion}

Signal peptide peptidase (SPP), which exists as a component of several different high molecular weight membrane-bound protein complexes, has important

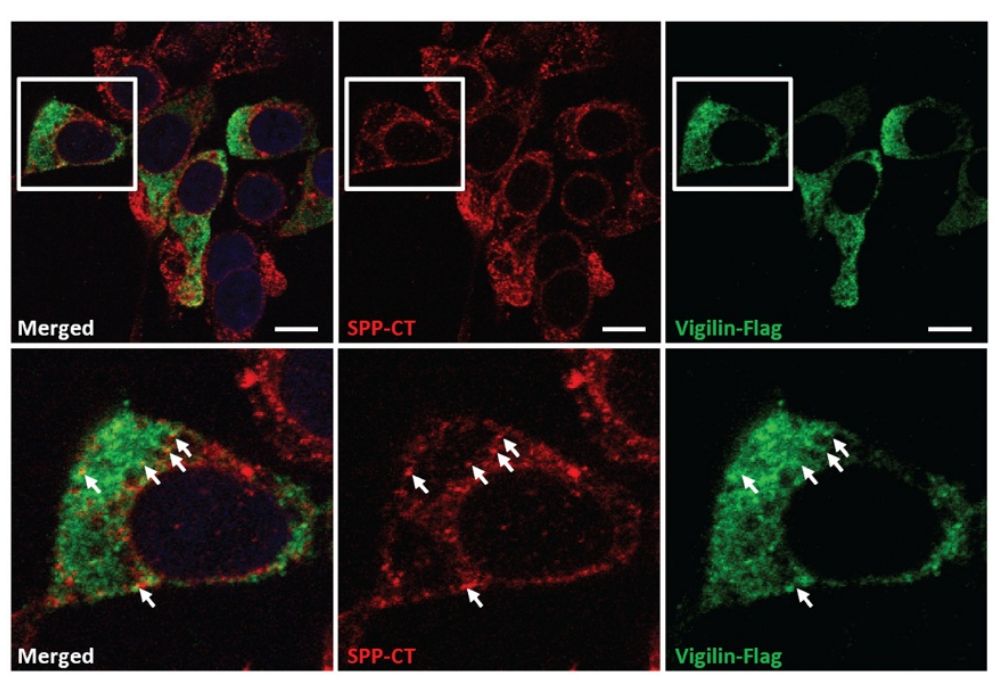

Figure 6 Vigilin co-localizes with SPP. HEK293 expressing vigilin-FLAG were immunostained with SPP-CT (red channel) and FLAG (green channel) antibodies, counter-stained with DAPI for the nuclei. Lower panel, magnified view of cell in white box from the top panel. Only a small proportion of vigilin co-localizes with SPP in vitro (examples of co-localization are indicated by white arrows in the magnified images). The white bar represents $10 \mu \mathrm{m}$ 

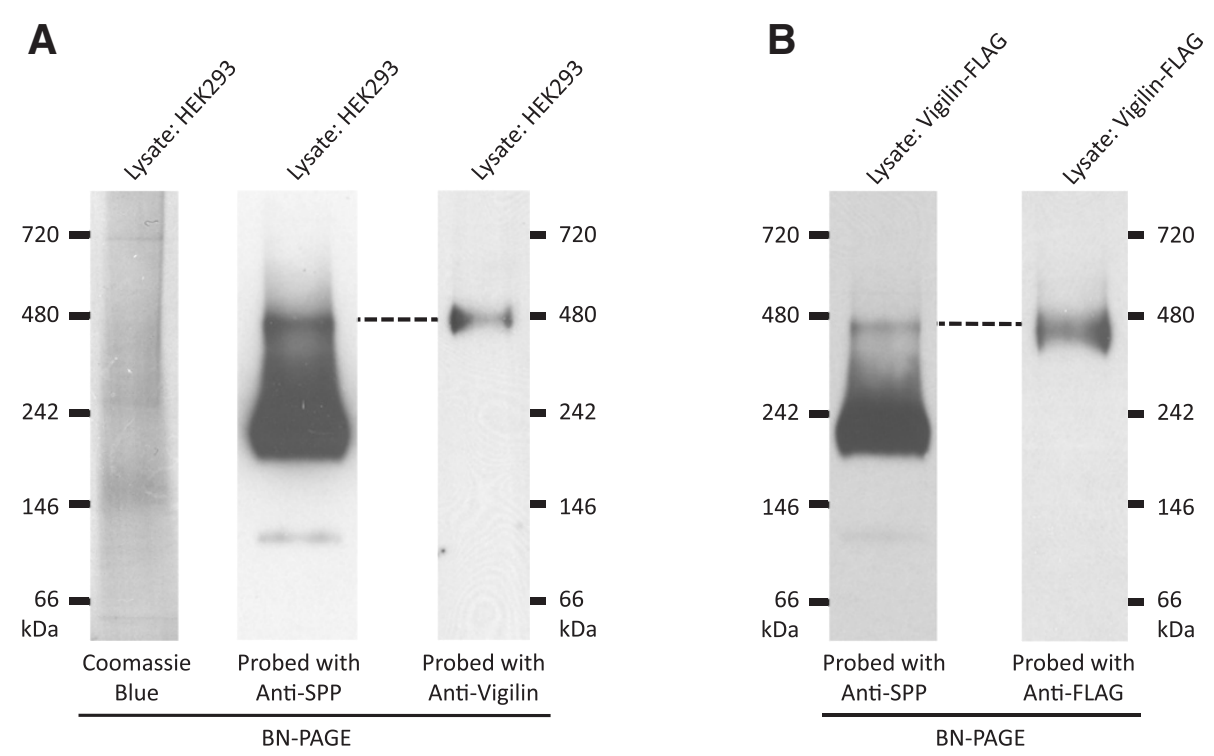

Figure $\mathbf{7}$ Vigilin is part of the $\mathbf{4 5 0}$ kDa SPP complex. (A) HEK293 cell lysate were solubilized in 0.5\% DDM and resolved on 4-16\% BN-PAGE gels. As shown on the left panel, SPP formed three distinct complexes at $450 \mathrm{kDa}, 200 \mathrm{kDa}$ and $100 \mathrm{kDa}$. Lysates probed with anti-vigilin antibody reveals that endogenous vigilin only forms one distinct complex on the BN-PAGE and that band co-migrates with the $450 \mathrm{kDa}$ SPP complex. Lysates were also Coomassie stained to show that the $450 \mathrm{kDa}$ SPP and vigilin containing complex was not a compression artifact of BN-PAGE gels, such as the band migrating at $700 \mathrm{kDa}$. (B) HEK293 vigilin-FLAG cell lysate were solubilized in 0.5\% DDM and resolved on 4-16\% BN-PAGE gels reveal that vigilin-FLAG also co-migrates with the $450 \mathrm{kDa}$ SPP complex only. Data shown are representative blots from three independent experiments.

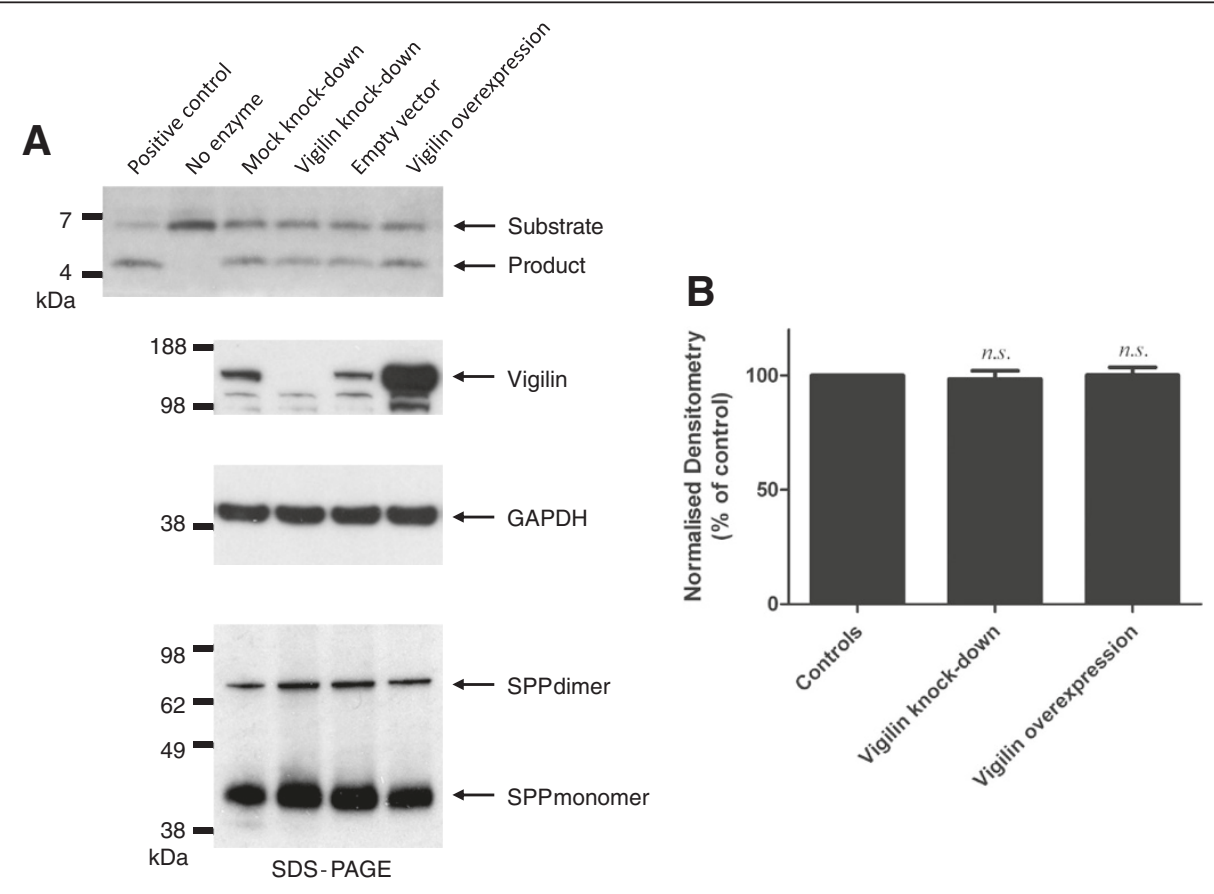

Figure 8 Vigilin expression level does not alter the protease activity of SPP. (A) The knockdown and over-expression of vigilin did not substantially alter the ability of SPP to cleave the prolactin substrate in the in vitro SPP assay. The positive control used in this study is a purified yeast homolog of SPP that cleaves the prolactin signal peptide substrate, while the negative control is set up without the addition of proteins. Expression level of vigilin was compared to the loading control, GAPDH. Total lysate concentration was adjusted to ensure equal loading of protein samples into the reaction. Data shown are representative blots from three independent experiments. (B) Densitometry analysis of three independent knockdown/overexpression and reactions. Bars represent mean \pm s.e.m. The unpaired $t$-test was performed using Prism (n.s., not significant, p-value > 0.05). 
proteolytic and non-proteolytic functions [1,5-7]. The latter functions, which are not well-characterized, may relate to protein quality control.

The biochemical and cellular data presented here suggest that the SPP-vigilin interaction is genuine and highly selective, although it is also clear that only a minor proportion of both proteins are involved in this interaction. Despite this seemingly minor interaction, vigilin molecules interact with SPP with high affinity on the basis that despite a high concentration of DDM in the solubilization step, the interaction between SPP and vigilin was still preserved. This interaction is also highly selective for SPP in high molecular weight complexes, both in immunoprecipitation and BN-PAGE experiments. There is considerable uncertainty about whether monomeric, dimeric or higher-order oligomers of SPP are catalytically active [7-9,14]. However, some evidence suggests that the higher-order species may not be catalytically active. If correct, as discussed below, this would suggest that the interaction of vigilin with these higherorder oligomers of SPP may relate to a non-proteolytic SPP activity.

A possible function of vigilin is to modulate the activity of SPP. Indeed, one obvious hypothesis is that vigilin might affect the proteolytic activity of SPP in a manner analogous to the selective modulating effect of TMP21 [15] and gSAP [16] on presenilin complex-mediated $\gamma$ secretase activity. However, unexpectedly, we found that neither vigilin knockdown nor overexpression had any effect on the proteolytic activity of SPP. It is also possible that SPP may modulate the biological activity of vigilin, although this could not be tested as no vigilin-specific biochemical assay exists.

An alternative effect of the SPP-vigilin interaction is that vigilin could modulate the putative functions of SPP in protein quality control in the ER. Testing this hypothesis will require much further work, and is beyond the focus of the current paper. However, vigilin has previously been shown to bind RNA, presumably via its $\mathrm{KH}$ domains [17-19], and can be localized with free and membrane-bound ribosomes [11-13]. The binding of mRNA by vigilin may stabilize the mRNA molecules and could be required for the localization of mRNA to actively translating ribosomes [11,20-22]. This observation, together with SPP's putative function in binding misfolded protein, suggests that the vigilin-SPP complex could potentially be involved in the translation and quality control of membrane proteins. For instance, the vigilin-SPP interaction could ensure that SPP is near to the site of newly synthesized polypeptides destined for insertion into the ER membrane. If so, this might allow the vigilin-SPP complex to be involved in the regulation of translation and the binding/removal of newly-made misfolded membrane proteins. The latter might be achieved by a combination of: 1) dislocation/translocation back across the ER membrane (as shown for SPP's role with MHC Class I molecules [5]); and 2) proteolytic cleavage of fragments in the membrane itself.

\section{Conclusions}

Using an unbiased iTRAQ mass spectrometry-based approach, we have identified the multi-KH domain protein vigilin as a potential interacting protein of SPP among the 78 proteins identified. We have confirmed the interaction between SPP and vigilin using a series of experiments that included co-immunoprecipitations, subcellular fractionation, native gel and co-localization studies. Vigilin does not appear to modulate the protease activity of SPP but instead vigilin-SPP complex could have a role in membrane protein quality control in the ER.

\section{Methods}

Antibodies and resins

The following antibodies were used in this study: rabbit anti-SPP C-terminus polyclonal antibody (SPP-CT, Abcam, Cambridge, UK), rabbit anti-SPP N-terminus polyclonal antibody (SPP-NT, Abcam), rabbit anti-vigilin polyclonal antibody (Abcam), rabbit anti-SPPL2b polyclonal antibody (Abcam) mouse anti-FLAG monoclonal antibody (Clone M2, Sigma-Aldrich, Dorset, UK), rabbit anti-GM130 polyclonal antibody (Abcam), rabbit anticalnexin polyclonal antibody (Abcam) and mouse antimyc monoclonal antibody (Invitrogen). The HA-agarose and FLAG-agarose affinity gels were obtained from Sigma-Aldrich and Protein G-sepharose was from GE Healthcare (Little Chalfont, UK).

\section{Molecular cloning}

Vigilin cDNA (ORFeome clone number: 100011448) was amplified by PCR using the forward (sequence: 5'-GGCGCCATGAGTTCCGTTGCAGTTTTG-3') and reverse (sequence: 5'-GGCCGGTTACTACTTGTCATCGTCATCCTTGTAGTCTCGTTTGGGGC CCCAAGGGAG-3') primers and inserted into the TA-cloning site of the pcDNA3.3 mammalian expression vector (Invitrogen, Paisley, UK) with a single FLAG tag (N-DYKDDDDK-C) introduced directly to the $\mathrm{C}$-terminus of the vigilin cDNA.

\section{Cell culture, transfection and siRNA knockdown}

Human Embryonic Kidney 293 (HEK293) cells were cultured in Dulbecco's modified Eagle's medium (DMEM, Sigma-Aldrich) containing $10 \%$ fetal bovine serum and $1 \%$ penicillin/streptomycin. Following sequence verification, the pcDNA3.3-vigilin-FLAG plasmid was transfected into HEK293 cells with FuGene 6 (Roche Applied Science, Burgess Hill, UK). Stable transfectants were clonally selected with $1 \mathrm{mg} / \mathrm{ml}$ Geneticin G418. Knock- 
down of SPP and Vigilin were achieved with SMARTpool siRNA (Dharmacon, Epsom, UK), which was transfected into HEK293 cells using the Dharmafect 1 reagent (Dharmacon) and, subsequently, incubated for 72-96 h.

\section{Membrane preparation and affinity purification of endogenous SPP}

Antibodies were cross-linked to Protein G sepharose with $0.025 \mathrm{M}$ Borax pH 9.45 in the presence of $20 \mathrm{mM}$ dimethylpimedilate (Sigma-Aldrich) and residual uncross-linked antibody was removed with $100 \mathrm{mM}$ glycine $\mathrm{HCl} \mathrm{pH} \mathrm{3.0.} \mathrm{For} \mathrm{the} \mathrm{preparation} \mathrm{of} \mathrm{microsomal}$ membranes, the cell pellet was resuspended and homogenized in sucrose lysis buffer (25 mM HEPES pH 7.4, 4 mM EDTA, $0.25 \mathrm{M}$ sucrose, complete protease inhibitor cocktail (Roche)). Following centrifugation at 2,000 $\times g$ for $10 \mathrm{~min}$, the supernatant was further centrifuged at $100,000 \times g \quad$ (Ti45 rotor, Beckman Coulter, High Wycombe, UK) for $60 \mathrm{~min}$ to isolate microsomal membranes. Membrane lysates were solubilized with $0.5 \%$ (wt/vol) $\mathrm{n}$-dodecyl- $\beta$-D-maltoside (DDM, Anatrace) in HEPES buffer (25 mM HEPES pH 7.4, $150 \mathrm{mM} \mathrm{NaCl}, 4$ mM EDTA, complete protease inhibitor cocktail). Lysates were pre-cleared with pre-immune serum crosslinked to protein G sepharose overnight, and SPP was then purified with SPP-CT antibody cross-linked to protein G sepharose. Next, the beads were subjected to at least 5 washes with HEPES buffer containing $0.02 \%$ (wt/ vol) DDM and a single high-salt wash step in HEPES buffer with $300 \mathrm{mM} \mathrm{NaCl}$. SPP and its interacting proteins were eluted by $\mathrm{pH}$ drop with Tris- $\mathrm{HCl} \mathrm{pH}$ 3.0. To generate a negative control, anti-SPP antibody was presaturated with $100 \mu \mathrm{g} / \mathrm{ml}$ of cognate peptide (sequence: N-TESKEGTEASASKGLEKKEK-C) and washes with 100 $\mu \mathrm{g} / \mathrm{ml}$ of the aforementioned peptide was also included.

\section{Protein reduction, alkylation and trypsinization}

Protein-containing fractions were denatured in the presence of $9 \mathrm{M}$ urea, followed by reduction with $5 \mathrm{mM}$ tris-(2-carboxyethyl)-phosphine for $30 \mathrm{~min}$ at $60^{\circ} \mathrm{C}$ and alkylation with $9 \mathrm{mM}$ 4-vinylpyridine for $1 \mathrm{~h}$ at room temperature in the dark. Samples were diluted five-fold to ensure that the concentration of urea did not exceed $2 \mathrm{M}$. Tryptic digestion was initiated by the addition of $1 \%$ (wt/wt) of side chain-modified, TPCKtreated porcine trypsin and allowed to proceed at $37^{\circ} \mathrm{C}$ for $6 \mathrm{~h}$.

\section{ITRAQ labeling and mass spectrometry}

The steps for the labeling of peptides with iTRAQ reagents, two-dimensional separation of peptide mixtures by offline strong-cation exchange (SCX) and online reversed phase (RP) liquid chromatography and subsequent analysis by electrospray tandem mass spectrometry have been described previously [23]. Samples derived from control and SPP-specific purifications were iTRAQ-labeled with iTRAQ-116 and iTRAQ-117 reagents, respectively.

\section{Database searches}

Collision induced dissociation (CID) spectra were analyzed using ProteinPilot (Version 2.0, Applied Biosystems, MDS Sciex). The lists of candidate interacting proteins were subjected to the following filters: (i) all identifications of proteins had to be based on at least two CID spectra which passed the 95\% confidence score returned by the ProteinPilot software; (ii) assignments to non-iTRAQ-labeled peptides or CID spectra with individual confidence scores of less than $90 \%$ were not included in the calculation of enrichment ratios based on iTRAQ signature mass signal intensities. Raw iTRAQ ratios were corrected for impurity levels of individual reagent lots determined by the manufacturer. The mass tolerance range between expected and observed masses used for database searches was \pm 150 ppm for MS peaks, and $\pm 0.15 \mathrm{Da}$ for MS/MS fragment ions. All samples were searched against the International Protein Index (IPI) database disseminated through EMBL/EBI.

\section{Co-immunoprecipitations and western blotting}

Homogenized HEK293 cells were solubilized in ice-cold HEPES buffer with $0.5 \%$ DDM for $60 \mathrm{~min}$ and centrifuged at $100,000 \times g$ for $30 \mathrm{~min}$ to remove insoluble material. Co-immunoprecipitations were carried out with $500-1000 \mu \mathrm{g}$ of solubilized total lysate utilizing antibodies against SPP-CT, SPPL2b and FLAG-tag, with preimmune rabbit serum and antibody against the HA-tag serving as the control for the SPP/SPPL2b and FLAG IPs, respectively. After pre-clearing, lysates were incubated overnight at $4^{\circ} \mathrm{C}$ with antibody and Protein G Sepharose or pre-conjugated affinity resins. Resin was then washed five times with $0.02 \%$ DDM in HEPES buffer. The precipitated proteins were eluted with $1 \times$ sample buffer (LDS, Invitrogen). For immunoblotting, the samples were resolved on $12 \%$ Bis-Tris NuPAGE gels (Invitrogen), transferred onto polyvinylidene fluoride membranes (PVDF, Millipore, Watford, UK) and probed with appropriate primary and secondary antibodies.

Blue native-polyacrylamide gel electrophoresis (BN-PAGE) Membrane lysates solubilized in $0.5 \%$ DDM were resolved on one-dimensional BN-Page (4-16\% NativePAGE Bis-Tris gels, Invitrogen), incubated in 1\% SDS for $15 \mathrm{~min}$ and transferred onto PVDF membranes for Western Blot analysis. For the second dimension SDSPAGE, the lanes from the BN-PAGE were excised and resolved on SDS-PAGE gels (12\% Bis-Tris NuPage gels, Invitrogen). 


\section{Subcellular fractionation on iodixanol gradients}

HEK293 cells were homogenized in Tris buffer $(25 \mathrm{mM}$ Tris pH 7.4, $25 \mathrm{mM} \mathrm{NaCl}, 130 \mathrm{mM} \mathrm{KCl,} 1 \mathrm{mM}$ EGTA, complete protease inhibitor cocktail) and centrifuged at $1,000 \times g$ for $10 \mathrm{~min}$ then at $3,000 \times g$ for $10 \mathrm{~min}$. The resulting supernatant was placed on top of a step gradient consisting of $1 \mathrm{ml}$ layers of 30, 25, 20, 15, 12.5, 10, 7.5 , 5, and $2.5 \%$ (vol/vol) iodixanol (Sigma-Aldrich) in Tris buffer. Following centrifugation at $92,000 \times g(\mathrm{SW} 40$ rotor, Beckman Coulter) for $30 \mathrm{~min}, 11$ fractions were collected from the bottom of the centrifuge tube. The fractions were analyzed for the presence of the SPP, vigilin and protein markers of the subcellular organelles.

\section{Immunofluorescence microscopy}

HEK293 cells were plated onto cover-slips pre-coated with $0.01 \%$ (wt/vol) poly-L-lysine solution (SigmaAldrich). HEK293 cells were fixed with $10 \%$ (vol/vol) formalin, perforated with PBS-T $(1 \times \mathrm{PBS}$ with $0.1 \%$ (vol/ vol) Triton X-100) and blocked with $10 \%$ (vol/vol) normal goat serum (Abcam) in PBS-T. Cells were incubated for $60 \mathrm{~min}$ in anti-SPP and anti-vigilin primary antibodies diluted in 10\% normal goat serum and subsequently incubated in the appropriate species-specific Alexa fluorescent dye conjugated secondary antibodies (Invitrogen) for $30 \mathrm{~min}$. The immunostained cells were viewed by confocal microscopy (LSM510 META, Carl Zeiss, Welwyn Garden City, UK).

\section{In vitro SPP activity assay}

The proteolytic activity of SPP was determined using an in vitro assay with $m y c$ and FLAG double tagged peptide derived from the signal peptide of prolactin [14] as the substrate. Briefly, the final SPP assay mixture $(40 \mathrm{mM}$ HEPES pH 7.0, $200 \mathrm{mM}$ sucrose, $4 \mathrm{mM}$ EDTA, $0.5 \mu \mathrm{M}$ substrate, $10 \mathrm{mM} \beta$-mercaptoethanol, $0.2 \%$ (wt/vol) polar lipids extracted from Escherichia coli (Avanti, Alabaster, AL, USA), complete protease inhibitor cocktail and cellular lysates) was incubated on ice for $30 \mathrm{~min}$ to allow substrate binding and the reaction was carried out at $30^{\circ}$ $\mathrm{C}$ for $2-4 \mathrm{~h}$. The reaction was stopped by the addition of sample loading buffer. Substrate and product bands were separated on 16\% Tricine gels (Invitrogen) and probed with anti-myc antibody. Reaction product and GAPDH band intensities were estimated using the ImageJ software package (version 1.45l, US National Institutes of Health, Bethesda, MD, USA) and the unpaired $t$-test was performed using the Prism statistical software package (version 5, GraphPad, La Jolla, CA, USA).

\section{Additional file}

Additional file 1: Complete list of peptides identified in the iTRAQ mass spectrometry analysis of SPP interacting proteins. Vigilin or
SPP-derived peptides were selectively enriched in the SPP purification sample compared to the control purification, while all other proteins identified had iTRAQ 117:116 ratios of less than 1.5.

\section{Abbreviations}

BN-PAGE: Blue native-polyacrylamide gel electrophoresis; CID: Collisioninduced dissociation; DDM: N-dodecyl- $\beta$-D-maltoside; ER: Endoplasmic reticulum; gSAP: Gamma-secretase activating protein; MS: Mass spectrometry; iTRAQ: Isobaric tag for relative and absolute quantitation; SPP: Signal peptide peptidase.

\section{Competing interests}

The author(s) declare that they have no competing interests.

\section{Authors' contributions}

PStGH and GSU conceived the study and participated in its design and coordination. SHJL, AHWJ, GSU, and WM performed the experiment. All authors analysed the data, prepared and approved the final manuscript.

\section{Acknowledgements}

This work was supported by grants from the Wellcome Trust, Howard Hughes Medical Institute, the Canadian Institutes of Health Research, and the Alzheimer Society of Ontario.

Received: 16 January 2012 Accepted: 4 May 2012

Published: 18 May 2012

\section{References}

1. Weihofen A, Binns K, Lemberg MK, Ashman K, Martoglio B: Identification of signal peptide peptidase, a presenilin-type aspartic protease. Science 2002, 296:2215-2218.

2. Fluhrer $R$, Steiner $H$, Haass $C$ : Intramembrane proteolysis by signal peptide peptidases: a comparative discussion of GXGD-type aspartyl proteases. J Biol Chem 2009, 284:13975-13979.

3. McCarthy JV, Twomey C, Wujek P: Presenilin-dependent regulated intramembrane proteolysis and gamma-secretase activity. Cell Mol Life Sci 2009, 66:1534-55.

4. Weihofen A, Lemberg MK, Ploegh HL, Bogyo M, Martoglio B: Release of signal peptide fragments into the cytosol requires cleavage in the transmembrane region by a protease activity that is specifically blocked by a novel cysteine protease inhibitor. I Biol Chem 2000, 275:30951-30956.

5. Loureiro J, Lilley BN, Spooner E, Noriega V, Tortorella D, Ploegh HL: Signal peptide peptidase is required for dislocation from the endoplasmic reticulum. Nature 2006, 441:894-897.

6. Crawshaw SG, Martoglio B, Meacock SL, High S: A misassembled transmembrane domain of a polytopic protein associates with signal peptide peptidase. Biochem J 2004, 384:9-17.

7. Schrul B, Kapp K, Sinning I, Dobberstein B: Signal peptide peptidase (SPP) assembles with substrates and misfolded membrane proteins into distinct oligomeric complexes. Biochem J 2010, 427:523-534.

8. Nyborg AC, Herl L, Berezovska O, Thomas AV, Ladd TB, Jansen K, Hyman BT, Golde TE: Signal peptide peptidase (SPP) dimer formation as assessed by fluorescence lifetime imaging microscopy (FLIM) in intact cells. Mol Neurodegener 2006, 1:16.

9. Nyborg AC, Kornilova AY, Jansen K, Ladd TB, Wolfe MS, Golde TE: Signal peptide peptidase forms a homodimer that is labeled by an active sitedirected gamma-secretase inhibitor. J Biol Chem 2004, 279:15153-15160.

10. Rath A, Glibowicka M, Nadeau VG, Chen G, Deber CM: Detergent binding explains anomalous SDS-PAGE migration of membrane proteins. Proc Natl Acad Sci USA 2009, 106:1760-1765.

11. Kruse C, Willkomm D, Gebken J, Schuh A, Stossberg H, Vollbrandt T, Müller PK: The multi-KH protein vigilin associates with free and membranebound ribosomes. Cell Mol Life Sci 2003, 60:2219-2227.

12. Vollbrandt T, Willkomm D, Stossberg H, Kruse C: Vigilin is co-localized with 805 ribosomes and binds to the ribosomal complex through its C-terminal domain. Int J Biochem Cell Biol 2004, 36:1306-1318.

13. Batlle M, Marsellach FX, Huertas D, Azorín F: Drosophila vigilin, DDP1, localises to the cytoplasm and associates to the rough endoplasmic reticulum. Biochim Biophys Acta 2011, 1809:46-55. 
14. Sato T, Nyborg AC, Iwata N, Diehl TS, Saido TC, Golde TE, Wolfe MS: Signal peptide peptidase: biochemical properties and modulation by nonsteroidal antiinflammatory drugs. Biochemistry 2006, 45:8649-8656.

15. Chen F, Hasegawa H, Schmitt-Ulms G, Kawarai T, Bohm C, Katayama T, Gu Y, Sanjo N, Glista M, Rogaeva E, Wakutani Y, Pardossi-Piquard R, Ruan X, Tandon A, Checler F, Marambaud P, Hansen K, Westaway D, St GeorgeHyslop P, Fraser P: TMP21 is a presenilin complex component that modulates gamma-secretase but not epsilon-secretase activity. Nature 2006, 440:1208-1212.

16. He G, Luo W, Li P, Remmers C, Netzer WJ, Hendrick J, Bettayeb K, Flajolet M, Gorelick F, Wennogle LP, Greengard P: Gamma-secretase activating protein is a therapeutic target for Alzheimer's disease. Nature 2010, 467:95-98.

17. Kügler S, Grünweller A, Probst C, Klinger M, Müller PK, Kruse C: Vigilin contains a functional nuclear localisation sequence and is present in both the cytoplasm and the nucleus. FEBS Lett 1996, 382:330-334.

18. Musco G, Stier G, Joseph C, Castiglione Morelli MA, Nilges M, Gibson TJ, Pastore A: Three-dimensional structure and stability of the KH domain: molecular insights into the fragile X syndrome. Cell 1996, 85:237-245.

19. Kruse C, Grünweller A, Notbohm H, Kügler S, Purschke WG, Müller PK: Evidence for a novel cytoplasmic tRNA-protein complex containing the KH-multidomain protein vigilin. Biochem J 1996, 320:247-252.

20. Dodson RE, Shapiro DJ: Vigilin, a ubiquitous protein with $14 \mathrm{~K}$ homology domains, is the estrogen-inducible vitellogenin mRNA 3'-untranslated region-binding protein. J Biol Chem 1997, 272:12249-12252.

21. Cunningham KS, Dodson RE, Nagel MA, Shapiro DJ, Schoenberg DR: Vigilin binding selectively inhibits cleavage of the vitellogenin mRNA 3'untranslated region by the mRNA endonuclease polysomal ribonuclease 1. Proc Natl Acad Sci USA 2000, 97:12498-12502.

22. Goolsby KM, Shapiro DJ: RNAi-mediated depletion of the $15 \mathrm{KH}$ domain protein, vigilin, induces death of dividing and non-dividing human cells but does not initially inhibit protein synthesis. Nucleic Acids Res 2003, 31:5644-5653.

23. Watts JC, Huo H, Bai Y, Ehsani S, Jeon AHW, Shi T, Daude N, Lau A, Young R, Xu L, Carlson GA, Williams D, Westaway D, Schmitt-Ulms G: Interactome analyses identify ties of $\operatorname{PrP}$ and its mammalian paralogs to oligomannosidic $\mathrm{N}$-glycans and endoplasmic reticulum-derived chaperones. PLoS Pathog 2009, 5:e1000608.

doi:10.1186/1477-5956-10-33

Cite this article as: Lu et al:: Vigilin interacts with signal peptide peptidase. Proteome Science 2012 10:33.

\section{Submit your next manuscript to BioMed Central and take full advantage of:}

- Convenient online submission

- Thorough peer review

- No space constraints or color figure charges

- Immediate publication on acceptance

- Inclusion in PubMed, CAS, Scopus and Google Scholar

- Research which is freely available for redistribution

Submit your manuscript at www.biomedcentral.com/submit
() Biomed Central 